Goldschmidt 2021 Abstract

https://doi.org/10.7185/gold2021.5829

\title{
Mercury: the reduced planet
}

\author{
CAMILLE CARTIER ${ }^{1}$, BERNARD CHARLIER ${ }^{2}$ AND \\ OLIVIER NAMUR ${ }^{3}$ \\ ${ }^{1}$ Centre de Recherches Pétrographiques et Géochimiques \\ ${ }^{2}$ University of Liège \\ ${ }^{3}$ Katholieke Universiteit, Leuven
}

Presenting Author: camille.cartier@univ-lorraine.fr

Mercury, the innermost and smallest planet of the solar system, has been studied by two spacecrafts, Mariner 10 and MESSENGER, that revealed its unique physical and chemical characteristics. Mercury is made up of a large metallic core, a thin mantle, and a relatively thick crust produced by partial melting of the mantle followed by volcanic eruptions. The volcanic provinces that crop out at the surface have FeO-devoid, $\mathrm{MgO}$, and $\mathrm{SiO}_{2}$-rich compositions, and have the particularity of bearing large amounts of sulfur $(\approx 2 \mathrm{wt} . \%)$ and sodium $(\approx 2-7$ wt.\%), leading to an exotic mineralogy, similar to that of enstatite meteorites. The dark surface of Mercury, in particular near craters, has been linked to the presence of carbon $(\approx 3$ wt.\%), whose origin might be endogeneous. Using this information together with available data for some minor ( $\mathrm{Ti}, \mathrm{Cr}$, $\mathrm{Mn}, \mathrm{Cl}$ ) and trace elements (U, Th), we can unravel Mercury's interior. Geochemical models based on experimental partitioning and solubility data revealed that Mercury accreted and differentiated at very low $f \mathrm{O}_{2}$ conditions $(\approx 5.5 \log$ units below the $\mathrm{Fe}-\mathrm{FeO}$ equilibrium), making it the most reduced planet of the solar system. In such conditions, $\mathrm{Si}$ alloys in metallic melts; hence Mercury's core would contain between 8 and 20 wt.\% Si, consistent with its actual partly liquid state. Sulfur is lithophile and concentrates in the silicate during core formation, and precipitates in the form of $(\mathrm{Mg}, \mathrm{Ca}, \mathrm{Fe}) \mathrm{S}$ upon magma ocean crystallization. Ti, chalcophile, is not significantly depleted at Mercury's surface, indicating no massive sulfide layer at the top of the core, like otherwise proposed. Finally, carbon solubility in silicate melts is enhanced at low $\mathrm{fO}_{2}$, leading to the possibility that it dissolved massively in Mercury's magma ocean, and precipitated in the form of diamond or graphite during it subsequent cooling. Mystery remains about the origin of Mercury's high metal/silicate ratio, that may or may not be the consequence of forming in a low $\mathrm{fO}_{2}$ region of the protoplanetary disk. Also, the link between Mercury and enstatite meteorites remains unclear. The planet will be further explored by the BepiColombo mission that will enter Mercury's orbit in 2025. 